\title{
Natural Antioxidants: Functions and Benefits- An Article
}

\author{
M M Youssef*
}

Department of Food Science \&Technology, Faculty of Agriculture, University of Alexandria, Egypt Alexandria, Egypt

*Corresponding author: M M Youssef, Department of Food Science \&Technology, Faculty of Agriculture, University of Alexandria, Egypt.
Received Date: July 29, 2019

Published Date: September 23, 2019

\section{Mini Review}

Natural antioxidants possess strong potential to inhibit oxidative stress by controlling the formation and scavenging the free radicals, known as reactive oxygen species (ROS). The ROS is a collective term and including both oxygen radicals and several non-radical oxidizing agents that participate in the initiation and/ or propagation of chain reaction [1,2].
Plants are potential sources for natural antioxidants. Phenolic compounds are considered as the main ones responsible for the potent antioxidant activity of plants. These compounds have been associated with their free radical scavenging capability, their potential chelation of pro-oxidant metals and their role as reducing agents and quenchers of ROS (Figure 1) [3,4].

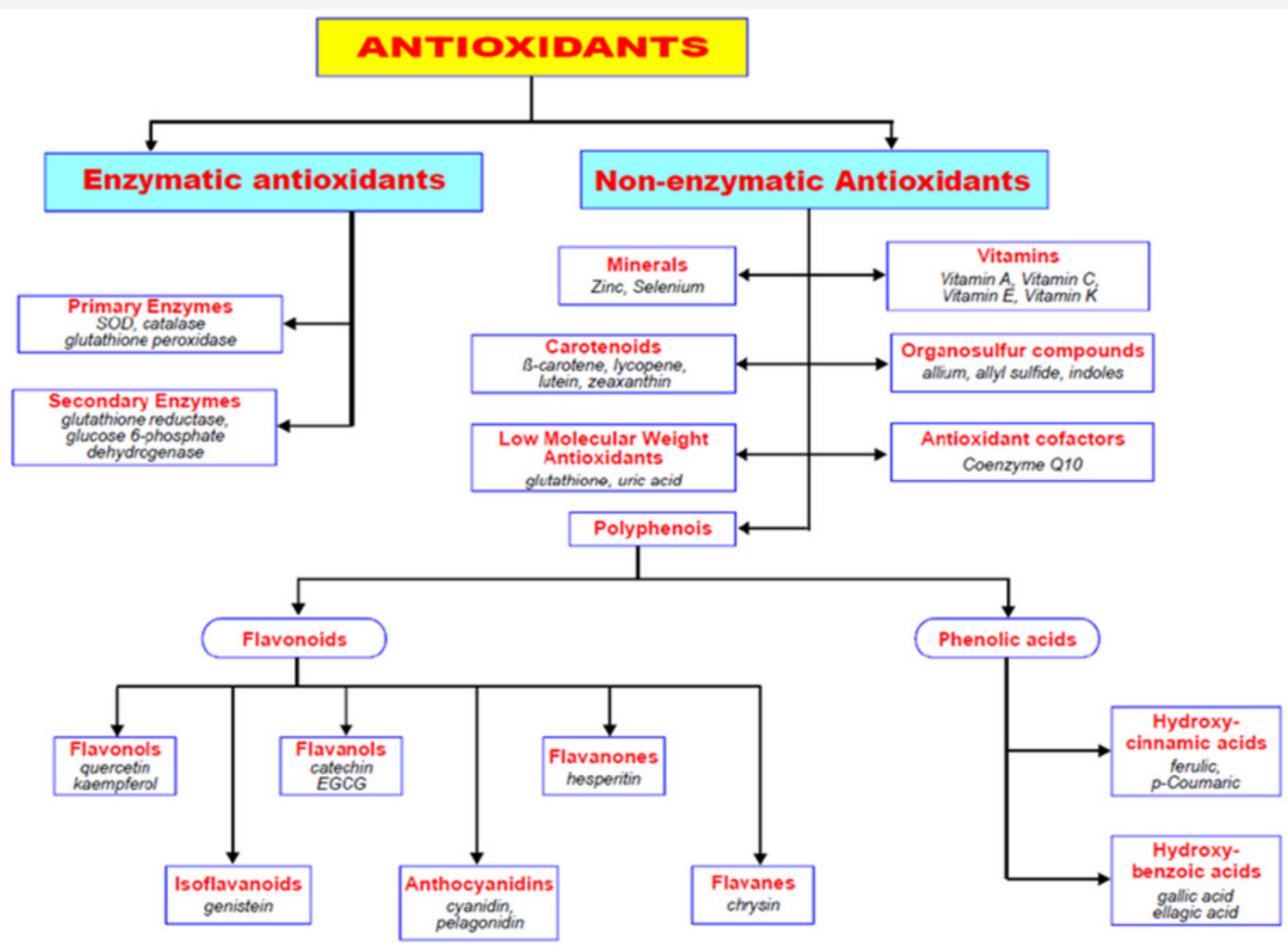

Figure 1: Classification of natural antioxidants. 
It is worth to mention that synthetic antioxidants have been used for decades however, recently they have rejected in a favour of natural antioxidants (Back to Nature). Antioxidants interrupt the free radical-mediated chain reactions and thereby preventing the lipid peroxidation process. Antioxidants can decrease the deleterious effects of various oxidative stress induced pathological conditions. (Figure 2) shows the mode of action of antioxidants. It is worth to mention that increase the concentration of free radicals results in elevation the oxidative stress on the living cell, and thereby is being fragile and susceptible for invasion by microorganisms including pathogenic ones. Moreover, high oxidative stress on the cell has been reported to be responsible for some degenerative diseases (Figure 2) [5,6].

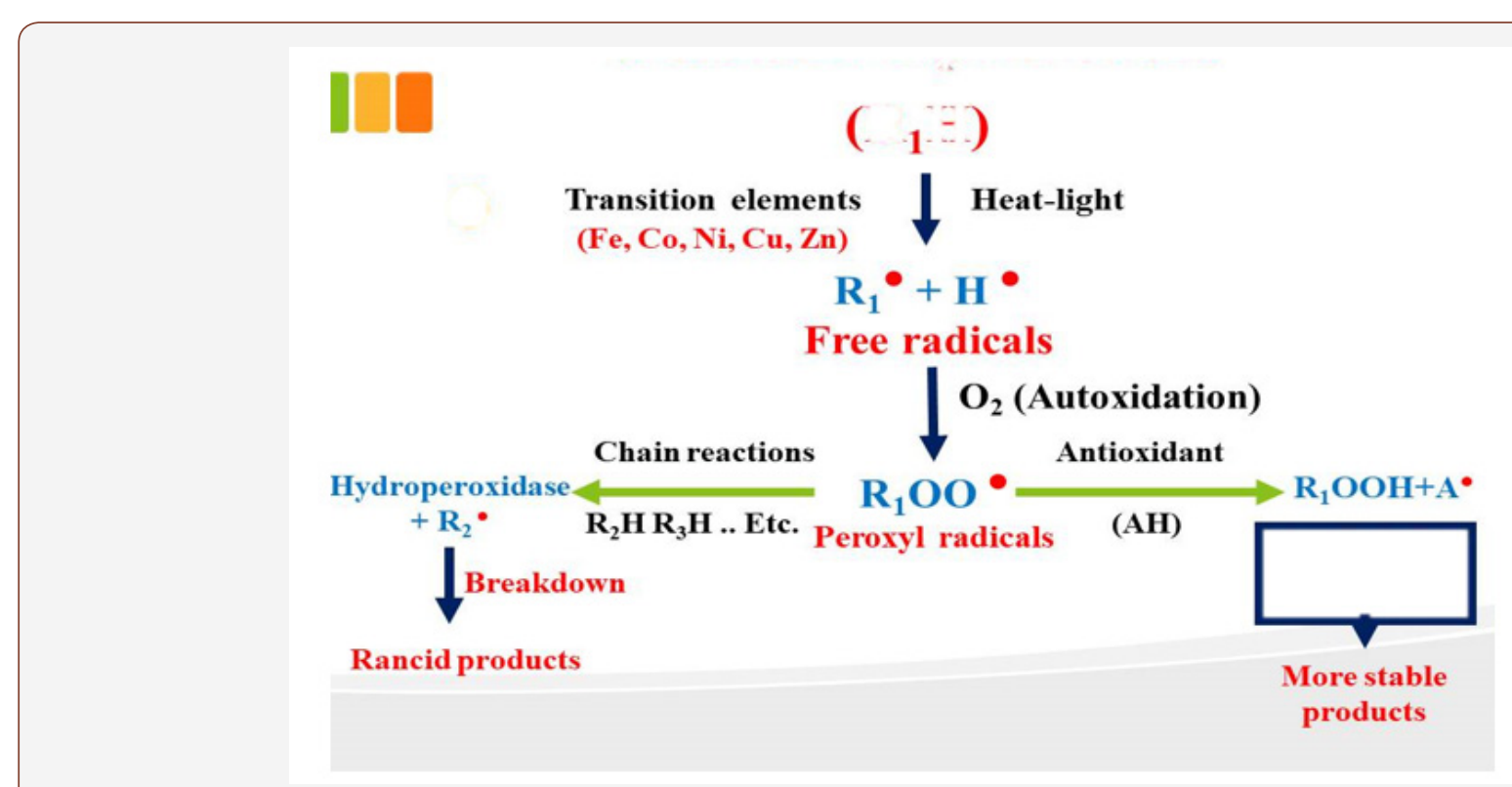

Figure 2: Mode of action of antioxidants.

There are two sources of free radicals, one from outside the living cell including: Stress, radiation exercise, smoke (active and passive) and pollution. The second source of free radicals is mitochondria inside the cell, since mitochondria is a factory of energy (ATP) and free radicals are the wastes of energy production process. Meanwhile, there are two sources of antioxidants, one inside the cell known as self-defense system including: Glutathion (GSH), superoxide dismutase and catalase while the second source of antioxidants is food [7,8]. Consequently, it is quite important to minimize the sources of free radicals and at the same time to increase the natural antioxidants present in a variety of food commodities.

\section{Acknowledgement}

None.

\section{Conflict of Interest}

No conflict of interest.

\section{References}

1. Abd El Wahab MG (2018) In vitro Assessment of Natural Antioxidants and their Applications in Meat Products. MSE Thesis, Faculty of Veterinary Medicine, Department of Food Hygiene, Alexandria University, Egypt.
2. Anbudhasan P, Surendrarai A, Karkuzhali S, Satthishkumarans S (2014) Natural antioxidants and its benefits: A Review International Journal of Food and Nutrition Science 3: 225-232

3. Nikmaram N, Budaraju S, Barba FJ, Lorenzo JM, Cox RB, et al. (2018) Application of plant extracts to improve the shelf life, nutritional and health related properties of ready-to eat meat products. Meat Science 145: 245-255.

4. Pateiro M, Lorenzoo J M, Amado IR, Franco D (2014) Effect of addition of green tea, chestnut and grape extract on the shelf-life of pig liver pate. Food Chem 147: 386-394.

5. Lorenzo JM, Pateiro M (2013) Influence of fat content on physicochemical and oxidative sfability of foal liver pate. Meat Sci 95(2): 330-335.

6. Ramana KV, Aramati Reddy BM, Majeti RK, Singhal SS (2018) Editorial therapeutic potential of natural antioxidant. Oxid Med Cell Longev p: 3.

7. Granato D;Nunes DS, Barba FJ (2017) An integrated strategy between food chemistry biology, nutrition, pharmacology and statistics in the development of functional food: A proposal. Trends in Food Science and Technology 62: 13-22.

8. Zhu A, Guan Q, Koubaa M, Barba FJ, Roohinejad S, et al. (2017) HPLCDAD-ESI-MS2 analytical profile of extracts obtained from purple sweet potato after green ultrasound assisted extraction. Food Chemistry 215: 391-400. 